\title{
Diversity in the use of pregnancy-related care among ethnic groups in Guatemala
}

\author{
Sofie De Broe
}

\begin{abstract}
Objective This study investigated ethnic differentials in the use of pregnancy-related care and aimed to identify whether the differences persist when geographical access to services is equal. This study was based in the northeastern Ch'orti area of Guatemala, an area characterised by a mixed ladino (of Spanish descent) and Maya (Ch'orti) culture.
\end{abstract}

Methods Data from a household survey carried out in 2001 in the town of Jocotán, and a previous survey carried out in 1994 in two nearby indigenous villages (aldeas), were used in this study. Logistic regression was used to explore the data. Unlike the Demographic and Health Survey (DHS) (1998-1999) that classifies ethnic groups according to dress and language, this study introduced an alternative approach based on self-identification.

Results The results showed significant differences and a gradient in the use of modern pregnancy care services among self-identified ethnic groups within the same town after controlling for socioeconomic and cultural indicators. Women of 'mixed' ethnicity had an intermediate behaviour between ladino and indigenous women. Women in the nearby aldeas almost solely relied on the traditional birth attendant for pregnancy-related care. The DHS data did not permit the detection of ethnic diversity in the use of pregnancy care for this region.

Conclusions Differences in the use of modern pregnancy care exist even among self-identified ethnic groups with no outward markers of ethnicity and persist when access to services is equal. For the majority of the population, living in indigenous villages, pregnancy care remains traditional. This ethnic diversity highlights the importance of further extending affordable, high-quality and culturally adapted maternal health care services in Guatemala.

J Fam Plann Reprod Health Care 2005; 31(3): 199-205 (Accepted 17 January 2005)

\section{Key message points}

- Ethnic diversity in the uptake of modern pregnancy-related care in Guatemala exists among ethnic groups with no outward markers of ethnicity when geographical access to service is equal.

- The Demographic and Health Surveys do not allow detection of the extent of ethnic diversity, which has a potential negative effect on the successful outcome of pubic health policies.

Division of Social Statistics, School of Social Sciences, University of Southampton, Southampton, UK Sofie De Broe, MSc, PhD Student

Correspondence to: Sofie De Broe, Division of Social Statistics, School of Social Sciences, University of Southampton, Highfield, Southampton SO17 1BJ, UK. Tel: +44 2380594082.

Fax: +44 2380 593846. E-mail: sofie@socsci.soton.ac.uk

\section{Introduction}

The maternal mortality rate in Guatemala is 184 per 100000 live births, which is among the highest in Latin America, and this figure is believed to be seriously underestimated. ${ }^{1,2}$ Whilst most causes of maternal mortality are preventable, the situation in Guatemala is particularly extreme, due to problems within the health care system and the quality of the maternal health care provided. 2,3 The institutional capacity of the health care system in Guatemala only covers one-fifth of birthing women. ${ }^{4,5}$ Maternal health care in Guatemala is described as highly fragmented and it consists of a combination of: reliance on household remedies, use of traditional care (the traditional birth attendant or comadrona, the traditional healer or curandero) and so-called 'formal', 'modern' private and public health care, which includes governmental health centres (GHCs) and clinics and private doctors. ${ }^{6-8}$ Overall, the majority of Guatemalan women give birth at home attended by the traditional birth attendant, often an elderly respected woman within the community with no medical training. ${ }^{9}$ Previous studies have highlighted the national differences in use of traditional and modern pregnancy-related care between and among ethnic groups. ${ }^{6,7}$ Guatemala has two main ethnic groups: the indigenous Mayas who speak more than 20 different languages and often wear their own traditional dress and the non-indigenous ladinos who speak Spanish and wear Western clothes. Ladino mothers are much more likely to use modern pregnancy-related care services than indigenous mothers, whereas the most traditional indigenous mothers are almost solely reliant on traditional health care or household remedies. ${ }^{6}$ The indigenous people in Guatemala, representing roughly half of the population, are characterised by high levels of illiteracy and social and economic exclusion from the modern sectors of the society. ${ }^{10}$ They mainly live in remote rural areas where access to services remains an important barrier to uptake of modern pregnancy-related care. ${ }^{8}$ Socioeconomic and cultural factors, and issues of quality of care at the modern health care facilities, continue to play a role in explaining why the vast majority of indigenous mothers exclusively rely on a traditional midwife compared with less than half of ladino mothers. ${ }^{6,7}$ Socioeconomic characteristics such as a woman's level of education and income, 8,11 and cultural factors such as a woman's health beliefs and autonomy, and the influence of her spouse and relatives, ${ }^{12,13}$ determine whether or not a woman will seek modern pregnancy-related care services.

All previous studies on ethnic differentials in Guatemala have struggled with the definition of ethnicity. Many studies [e.g. the Demographic and Health Survey (DHS) 1998-1999] have classified people into ethnic groups according to objective characteristics such as dress and language. The interviewers would classify people who spoke an indigenous language and wore traditional dress as indigenous; everyone else was classified as ladino. Yet defining ethnicity is a complex issue in the Guatemalan context. ${ }^{14}$ Most indigenous people are, in fact, descended from both the Mayas and the Spanish conquerors and the same is true of the ladinos or non-indigenous people. ${ }^{15} \mathrm{~A}$ further challenge to the would-be classifier of ethnic groups is the process of ladinisation, or "the tendency of 


\section{ARTICLE}

indigenous (Maya) people to acculturate by becoming ladinos and dropping indigenous cultural traits or traditions (language, dress, religion and customs)' ${ }^{16}$ In the process of ladinisation, the objective characteristics (dress and language) used in previous studies are often abandoned earlier than other features of Maya life and culture. Thus many people who neither wear traditional dress nor speak an indigenous language (and who would, according to the DHS, be classified as ladino) still regard themselves as indigenous. The misclassification of the ethnic groups has always obscured ethnic differences in reproductive behaviour in Guatemala and official numbers have tended to underestimate the proportion representing the indigenous population. ${ }^{17,18}$ Self-identification has been suggested as the key to overcoming the problem of defining ethnicity. ${ }^{16}$

This study used self-identification in order to classify ethnic groups and aimed to identify whether there are differences in the use of pregnancy-related care between the ethnic groups when geographical access to services is equal. Three research questions were addressed: (1) to identify which types of pregnancy-related care services are being used by the various (self-identified) ethnic groups within the town of Jocotán; (2) to identify which types of pregnancy-related care services are used in the nearby indigenous villages (aldeas), Tesoro Abajo and Pacrén; and (3) how can these differences, if any, be explained? The findings were then compared with the Guatemalan DHS 1998-1999 in order to determine to what extent a different

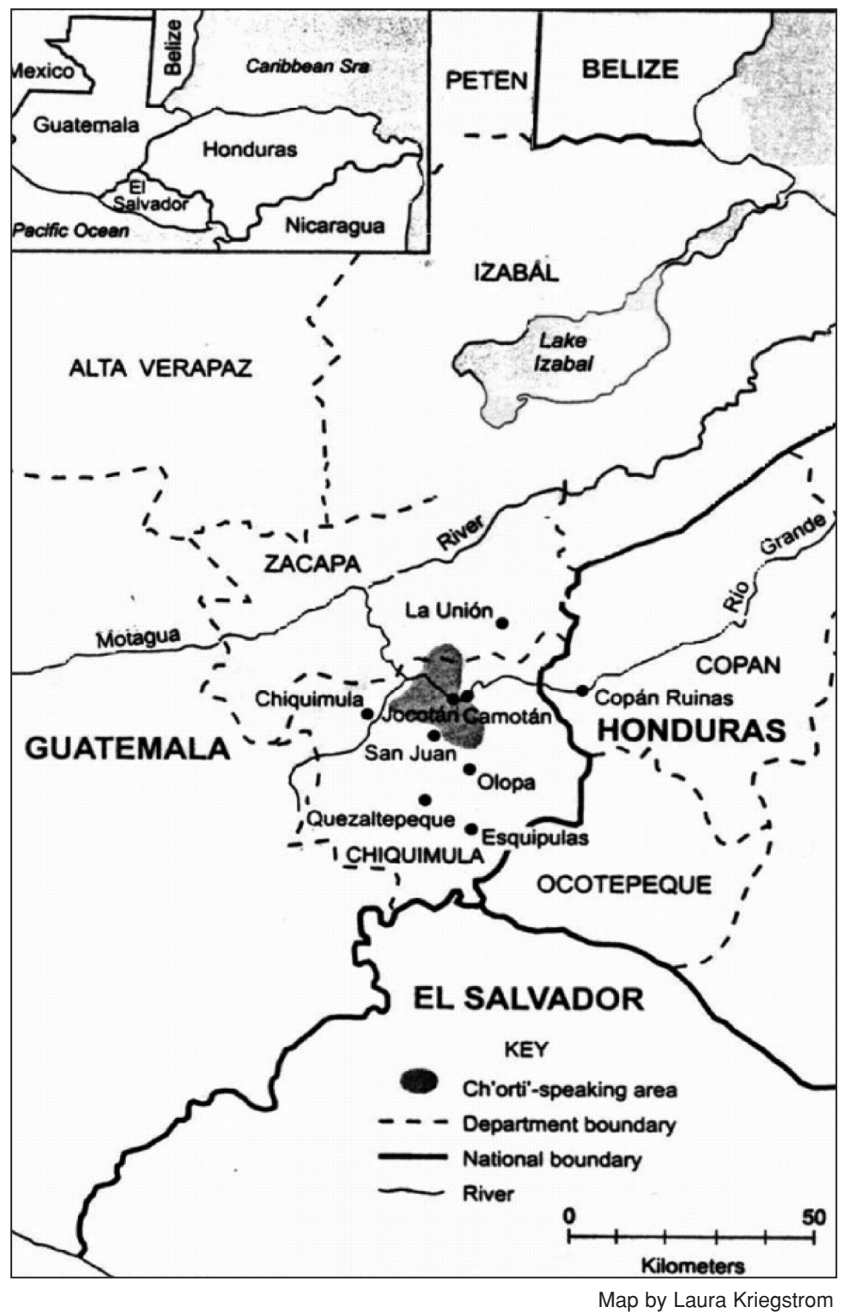

Figure 1 Location of the Ch'orti area. Source: Metz (2001). ${ }^{24}$ Figure reproduced with the permission of the journal Human Organization, the author Brent Metz and the maker of the map, Laura Kriegstrom definition of ethnicity gives different results. This study was located in the north-eastern region of Guatemala and focused on the understudied indigenous Ch'orti area.

\section{Study area}

The Ch'orti area (Figure 1) has a population of approximately 100000 people. ${ }^{20}$ The town of Jocotán is the capital of the municipio Jocotán and the administrative centre of the five municipios of the Ch'orti area. Jocotán town is divided into five districts (San Lorenzo, San Sebastian, El Cementerio-Nuevo, El Calvario and El Mitch) and is surrounded by 33 aldeas (indigenous villages). Geographical access to the different health care services is more or less the same for all women residing in Jocotán town. In terms of modern pregnancy-related care there are the private physicians' clinics that charge US \$7 per pre- or postnatal visit and the nurses and physicians at the GHC where services are free of charge. One of the main providers of health care services in the municipio of Jocotán is the dispensary referred to as 'Bethania'. The Bethania charges for health care but at reduced rates; a prenatal visit costs US \$2. Most of the indigenous people in the Ch'orti area rely solely on the GHC and the Bethania for general health care. Women who want to deliver or have a prenatal care visit in a hospital need to go to the hospital in the county capital of Chiquimula. Chiquimula is 1 hour's drive by car or by bus (hourly services) from Jocotán and the hospital charges vary between US \$10 and \$15 per prenatal visit.

Within the Ch'orti area, modern medical services are only available in Jocotán town, which is several hours' walking distance from most aldeas. For local health care services, the people from the aldeas rely on household remedies, a locally trained health worker (promoter de salud), a traditional healer (curandero), a traditional birth attendant (comadrona) and the 'ambulant' (mobile) doctor sent out by the GHC or the Bethania.

\section{Data and methods}

Jocotán (2001) and the aldeas (1994)

Data were collected via two surveys: the first carried out in the town of Jocotán and the second in two nearby aldeas, Pacrén and Tesoro Abajo. The results are compared to those from the 1998-1999 DHS sample for the north-eastern region.

The survey in Jocotán town was conducted in September 2001. Jocotán town has approximately 3750 inhabitants, of whom 985 are women of reproductive age. A stratified random sample was selected comprising 173 mothers aged between 15 and 49 years, who were evermarried or in union. No listing of households was available to use as a sampling frame, therefore a map of the residential houses was used for Jocotán, whereby every fifth house was selected for interview in the streets of the different districts. Only $10 \%$ of all selected women were not home at the second visit. In each household, one mother who was ever-married or in union was interviewed; in cases of an extended family, (the partner of) the head of the household was selected. None of the selected women refused to participate in the study and the interviews took approximately 45 minutes each. The questionnaire covered the following topics: demographic characteristics, household composition, educational level of all members in the household, marital status, living conditions, religion, ethnicity, working status, health care, pregnancy-related care, fertility and knowledge and use of family planning. The sample was stratified by district, with the probability of selection being proportionate to the size of each district. This yielded a sample of 173 mothers: $10 \%$ in San Lorenzo, 27\% in San Sebastian, 23\% in El CementerioNuevo, $27 \%$ in El Calvario and $13 \%$ in El Mitch. 
In 1994, a similar but more restricted survey was carried out in two of the 33 aldeas surrounding Jocotán: Pacrén and Tesoro Abajo. These are both near to Jocotán but different in their socioeconomic and cultural characteristics. In 1994, Pacrén had 1282 inhabitants and Tesoro Abajo 1251 inhabitants (Guatemala Census Data, 1994). Because of the restricted timeframe, the samples interviewed were restricted to ever-married or in union living mothers aged between 20 and 35 years. Half of the women in this age group were visited by selecting every second hut: 68 in Pacrén and 67 in Tesoro Abajo.

Variable measurement and operational definition. This study focused on the following pregnancy care outcomes: location and attendance during last delivery and use of pre- and postnatal care during or after the last pregnancy. Mothers were asked whether or not they had received at least one preor postnatal care (traditional or modern) visit during or after their last pregnancy, where it had taken place and who had attended them. No distinction was made between whether the mothers received a visit or whether she sought care herself and no specification was asked about the content of this visit. Attendance during delivery and prenatal care was provided by a skilled medical person (a Belgian nun, the auxiliary nurse or trained midwife, nurse or physician) or non-skilled personnel (the traditional birth attendant or a family member). In this survey the interviewer registered the birth attendant with the highest qualification whereas the DHS allowed multiple answers for this question. For the location of pre- and postnatal care, the private doctors' consultation room and the private clinic were combined because few mothers reported having gone to a private clinic and it was sometimes difficult to distinguish the two.

Ethnicity was measured through self-identification. The investigators asked the question: 'What do you consider yourself as? Indigenous or ladino?' Those who clearly said that they considered themselves indigenous, or who affirmed that they were ladino, were so classified. However, many respondents said they were not fully indigenous anymore, as they were living in Jocotán and were 'ladinised'. Some of these mothers said they considered themselves to be of 'mixed' ethnicity. Because of the small numbers, the ethnic groups 'mixed' and ladino were merged in some of the descriptive tables and the multivariate analysis. Both groups (ladino and 'mix' vs. indigenous) were composed of similar age groups. Marital status was classified as being currently married or in union or not. In the aldeas, the intermediate category was not suggested as all women considered themselves indigenous.

A variable for living conditions was created based on: ownership of the house or land; access to a private water tap; a flushing toilet; electricity; the type of walls, ceiling and floor; garbage disposal; and whether the kitchen was separate. Employment of the mothers was a two-category variable: 'working' (including women earning an income through home-based activities) or 'housewife'. Level of education was categorised as 'no education', 'primary education' (1-6 years at school) and 'secondary or higher education' (from 7 years at school onwards, including three women who had more than 12 years of education).

\section{Jocotán (2001)}

Variable measurement and operational definition. A separate variable was created to account for differences between the two major ethnic groups (ladino and 'mixed' vs. indigenous) in terms of health beliefs and exposure to modern cultural values. Sociocultural characteristics such as language and dress were irrelevant for Jocotán because hardly any of the women were speaking Ch'orti or wearing traditional dress. The use of household remedies in the village where biomedical drugs are available, and never having discussed family planning with one's partner despite proximity of family planning services suggests a more traditional background in terms of health care; not having a relative in the capital or abroad and having lived in an aldea previously suggests a more restricted social network. Each of those sociocultural indicators was given a one-point score in order to create a variable accounting for sociocultural characteristics.

One has to keep in mind that the data for the DHS refer to pregnancies that have taken place within the 5 years before the survey, whereas in the sample of the present study all births have been considered independently of when they occurred. This was justified as the study was mainly designed to detect differences in pregnancy-related care between ethnic groups in the town of Jocotán. The majority of mothers were living in Jocotán at the time of their last birth and the same pregnancy-related care services have been available in Jocotán for the last 20 years. None of the interviewed mothers had problems recalling the care they received during their last pregnancy. Reasons for nonuse of pre- and postnatal care among non-users were elicited with open questions allowing multiple answers.

For the multivariate analysis, the dependent variables are delivery at home as opposed to a clinical setting and whether the mother sought or received a prenatal care visit or not. Since most women who did not give birth at home gave birth in the hospital in Chiquimula, and very few gave birth in 'other medical facilities', these two categories were combined.

Study design. Logistic regression was used to detect whether ethnicity had an independent effect on delivery at home as opposed to a clinical setting and uptake of prenatal care during pregnancy after controlling for parity (measured in terms of number of pregnancies), age at first birth, marital status, living conditions, working outside of the house, educational level and sociocultural characteristics.

\section{Sample characteristics}

The five districts of Jocotán town and the two aldeas exhibit a wide range of social and economic conditions. Within the town, the districts of San Lorenzo, San Sebastian and El Calvario are older and more prosperous than El Cementerio-Nuevo and especially El Mitch. The latter are fairly new districts mainly inhabited by immigrants from the aldeas. El Mitch is so-named because it was originally constructed to house people rendered homeless by hurricane Mitch. Living conditions in the El Mitch district of Jocotán town and the two aldeas were worse than in other districts of Jocotán.

Half of the mothers in Jocotán town were working outside the household, a figure similar to that of urban areas in the north-eastern region as a whole. More than three-fifths of the women interviewed in the town considered themselves 'indigenous', $15 \%$ described themselves as 'mixed' and $23 \%$ said they were ladino. All spoke Spanish and only three wore traditional dress; only one spoke the indigenous Ch'orti language. As such, the population in Jocotán is composed of three self-identified ethnic groups with no outward markers of ethnicity and would be entirely classified as ladino by the DHS. The ethnic groups in Jocotán clearly differed in their socioeconomic characteristics. Ladino women were better educated, had better living conditions and were more likely to work outside the house than the other two ethnic groups. Women describing themselves as 'indigenous' scored the lowest on all socioeconomic indicators compared to the other ethnic groups (Table 1). 
ARTICLE

Table 1 Socioeconomic and cultural indicators for different ethnic groups of ever-married (in union) mothers aged 15-49 years in Jocotán town, 2001

\begin{tabular}{llcc}
\hline Indicator & $\begin{array}{c}\text { Indigenous 'Mixed' } \\
(n=109)\end{array}$ & $\begin{array}{c}\text { Ladino } \\
(n=25)\end{array}$ \\
\hline $\begin{array}{l}\text { Average number of years at school } \\
\text { Working outside the house (\%) }\end{array}$ & 4.0 & 7.7 & 9.8 \\
$\begin{array}{l}\text { Living in a house with an earth } \\
\quad \text { floor (\%) }\end{array}$ & 37 & 48 & 67 \\
$\begin{array}{l}\text { Belonging to the most traditional } \\
\text { category (\%) }\end{array}$ & 57 & 40 & 0 \\
& & & \\
\hline
\end{tabular}

Tesoro Abajo is an aldea that lies along the road from Jocotán to Chiquimula. It is more 'ladinised' (none of the mothers spoke Ch'orti or wore traditional dress) and had better living conditions than Pacrén (most households in Tesoro had water and half of them had electricity supply, whereas the majority of the households in Pacrén had neither water nor electricity supply). Most mothers in Pacrén spoke Ch'orti and wore traditional dress. All of the mothers in Pacrén were staying at home; a small group of mothers in Tesoro Abajo were working outside the house.

All the women in the aldeas considered themselves 'indigenous'. This finding is at variance with the 1998-1999 DHS results for the north-eastern region, in which there were (using the DHS definition of ethnicity) only four women living in a household where the members spoke Ch'orti. This suggests that the DHS definition of ethnicity is underestimating the proportion of women who consider themselves indigenous. Because of the very small proportion of women in the region described as 'indigenous' in the DHS sample, it proved impossible to compare the findings of this study about differentials in pregnancy-related care use by ethnicity with those reported in the DHS. Instead, a comparison was made using rural and urban residence as a stratifying variable, justified by the fact that the indigenous population are more likely to live in the rural areas whereas the ladino population are more likely to live in urban areas. ${ }^{14}$

\section{Results}

Delivery care

Place of last delivery and type of attendance during delivery differ greatly between the ethnic groups (Table 2). The majority of mothers in Jocotán who consider themselves 'mix' or ladino gave birth in the hospital at Chiquimula, whereas almost half of the indigenous mothers gave birth at home. In the aldeas, only a few mothers in Tesoro Abajo and two mothers in Pacrén gave birth in a hospital. In the north-eastern region, a large difference existed between the rural and urban areas. Correspondingly, large differences were observed between the ethnic groups for attendance during last delivery (Table 2). Most ladino and 'mix' mothers had a doctor attending them during their last delivery, whereas this was the case for less than half of the indigenous mothers. The remaining indigenous mothers mainly relied on a nurse, a midwife or a family member during delivery.

Twenty-two mothers in Jocotán reported having been assisted by a comadrona, or traditional birth attendant, during their last delivery. Two of these mothers had their last child in their aldea before moving to Jocotán but the remaining mothers were all living in Jocotan at the time of delivery. These mothers reported to have preferred the care of a known traditional birth attendant based in Jocotán above the modern pregnancy-related care available.

In Pacrén, family members were slightly more frequently consulted than the traditional birth attendant during last delivery, these being the two main types of birth attendants. In Tesoro Abajo, the traditional birth attendant was the most consulted attendant; about one-quarter of the mothers relied on family members. In the north-eastern region, most urban mothers reported having received attendance by a doctor or nurse and a smaller group had attendance from a trained midwife. In the rural areas of the north-eastern region, roughly one-third of mothers were attended by a family member; the doctor, nurse and midwife were equally consulted by one-quarter of mothers. Contrary to the findings for the aldeas around Jocotán, relatively few mothers relied on the traditional birth attendant.

\section{Pre-and postnatal care}

Almost all mothers in Jocotán received prenatal care, except for the indigenous mothers, of whom one-third did not receive prenatal care; among the indigenous and 'mix' mothers less than half received postnatal care (Table 2). Ladino mothers also had significantly more prenatal visits compared to the other two ethnic groups (Table 3 ). Compared to the mothers of Jocotán, similar proportions of mothers in the north-eastern region received prenatal care, whereas fewer received postnatal care.

In Jocotán, one-third of mothers consult the hospital in Chiquimula and one-third rely on the GHC for prenatal care (Table 3). The remaining mothers go to the Bethania or the private doctor. Again, ladino mothers are much more likely to go to the hospital in Chiquimula or see the private doctor than indigenous mothers. Most indigenous mothers go to the GHC or 'Bethania'; the remaining third goes to see the private doctor or the hospital in Chiquimula for

Table 2 Pregnancy-related care among ever-married or ever-in-union mothers

\begin{tabular}{|c|c|c|c|c|c|c|c|c|}
\hline \multirow[t]{2}{*}{ Pregnancy-related care indicator } & \multicolumn{4}{|c|}{ Jocotán (2001) } & \multicolumn{2}{|c|}{ Aldeas (1994)* } & \multicolumn{2}{|c|}{$\begin{array}{l}\text { North-eastern region } \\
(1998-1999) \dagger\end{array}$} \\
\hline & $\begin{array}{l}\text { Indigenous } \\
(n=107)\end{array}$ & $\begin{array}{l}\text { 'Mixed' } \\
(n=23)\end{array}$ & $\begin{array}{l}\text { Ladino } \\
(n=40)\end{array}$ & Total & $\begin{array}{l}\text { Tesoro } \\
(n=67)\end{array}$ & $\begin{array}{l}\text { Pacren } \\
(n=68)\end{array}$ & $\begin{array}{l}\text { Rural } \\
(n=331)\end{array}$ & $\begin{array}{l}\text { Urban } \\
(n=137)\end{array}$ \\
\hline \multicolumn{9}{|l|}{ Place of delivery } \\
\hline Home (vs. a clinical setting) $\ddagger$ & 40 & 13 & 7 & $28 \S$ & 87 & $97 \S$ & 70 & 18.5 \\
\hline \multicolumn{9}{|l|}{ Attendance at delivery } \\
\hline Midwife & 0 & 0 & 0 & 0 & 0 & 0 & 26 & 16 \\
\hline Husband/mother & 14 & 0 & 0 & 9 & 28 & 47 & 32 & 1 \\
\hline Traditional birth attendant & 18.5 & 4.5 & 2.5 & 13 & 51 & 44 & 12.5 & 2.5 \\
\hline No one & 5.5 & 0 & 0 & 3.5 & 9 & 7.5 & 2.5 & 0 \\
\hline Received prenatal care & 77 & 92 & 97.5 & $84 \S$ & NA & NA & 72.5 & 95 \\
\hline Received postnatal care & 41 & 39 & 75 & $49 \S$ & NA & NA & 10 & 25 \\
\hline
\end{tabular}

All figures given in the table are percentage values. *Sample in the aldeas limited to women between 20 and 35 years of age. †Source: 1998-1999 Guatemala Demographic and Health Survey (DHS)-weighted averages. $¥$ Includes the home of the traditional birth attendant for the DHS data. §Chi-square is statistically significant at $p<0.005$. NA, not available. 
Table 3 Location and attendance during pre-and postnatal care among ever-married or ever-in-union mothers

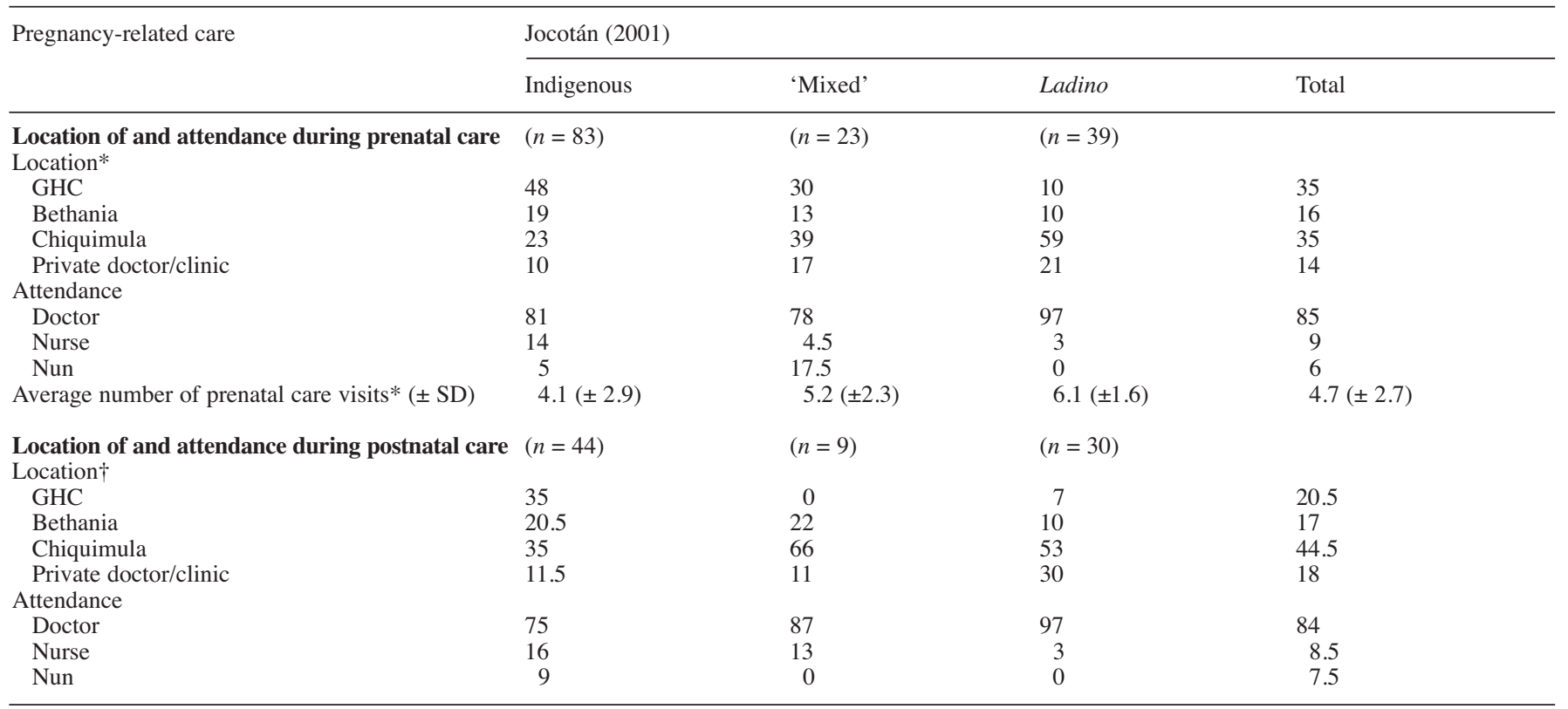

All figures given in the table are percentage values. *Statistically significant at $p<0.001$. $†$ Statistically significant at $p<0.01$. GHC, governmental health centre.

prenatal care. Mothers who consider themselves 'mix' have an intermediate behaviour between ladino and indigenous mothers. Even though the location of prenatal care differs between the ethnic groups, most mothers report having seen a doctor or nurse during the prenatal visit. Half of mothers in Jocotán who had postnatal care report to have been to the hospital in Chiquimula and $20 \%$ go to the GHC; the remaining mothers go to the 'Bethania' or the private doctor for postnatal care. Ladino and 'mix' mothers are the most likely to have been to the hospital in Chiquimula, whereas the indigenous mothers were as likely to go to the $\mathrm{GHC}$ as to the hospital. Overall, the uptake of postnatal care is low among all ethnic groups.

Reasons for non-use of prenatal care are mainly relevant for the indigenous mothers because most of the mothers of the other two ethnic groups received prenatal care (Table 4). Indigenous mothers reported not having the habit of taking up prenatal care and not finding it necessary. A smaller number of mothers found the services too expensive and had no confidence in them. Reasons for nonuse of postnatal care exist in both main ethnic groups. Most mothers do not find them necessary or they are not accustomed to using postnatal care. Some indigenous mothers reported that the services offered were too expensive, they did not have confidence in them or had to wait too long to be seen. Ladino and 'mix' mothers also reported this last reason for non-use of postnatal care services, whereas only one mother in this ethnic group reported not trusting the services.

Table 4 Reasons for not taking up pre- and postnatal care among nonusers in different ethnic groups: ever-married or ever-in-union women in users in different eth
Jocotán town, 2001

\begin{tabular}{lcclll}
\hline Reason & \multicolumn{2}{l}{ Indigenous } & & \multicolumn{2}{c}{ 'Mixed' or ladino } \\
\cline { 2 - 3 } \cline { 5 - 6 } & $\begin{array}{l}\text { Prenatal } \\
(n=25)\end{array}$ & $\begin{array}{l}\text { Postnatal } \\
(n=63)\end{array}$ & $\begin{array}{l}\text { Prenatal } \\
(n=3)\end{array}$ & $\begin{array}{l}\text { Postnatal } \\
(n=24)\end{array}$ \\
\hline Service understaffed & 0 & 0 & 1 & 0 \\
Waiting time too long & 1 & 4 & 0 & 3 \\
Too expensive & 7 & 9 & 0 & 0 \\
Too far away & 2 & 3 & 0 & 0 \\
Not necessary & 9 & 41 & & 20 \\
Not accustomed to use & 13 & 10 & 0 & 2 \\
No confidence in service & 3 & 7 & 3 & 1 \\
\hline
\end{tabular}

Table 5 Odds ratios (with 95\% CIs) from a logistic regression analysis of the probability of given last birth at home as opposed to a clinical setting among mothers in Jocotán town, 2001

\begin{tabular}{lrrl}
\hline Covariate* $^{*}$ & OR & $95 \%$ CI & $p$ \\
\hline 'Mixed' or ladino & 1.00 & & \\
Being indigenous & 10.57 & $2.24-49.88$ & $<0.005$ \\
No education & 13.42 & $3.27-55.14$ & $<0.001$ \\
Primary education & 3.04 & $0.76-12.19$ & NS \\
Secondary or higher education & 1.00 & & \\
Parity & 1.21 & $1.01-1.46$ & $<0.05$ \\
Log likelihood & -68.32 & & \\
\hline
\end{tabular}

*Other controls included in the model were the woman's sociocultural characteristics, marital status, working outside of the house, age at first birth and living conditions. OR, odds ratio; NS, not significant.

In the logistic regression model several variables remained significant to explain the probability of giving birth at home as opposed to a clinical setting, when ethnicity was introduced as a separate variable. After controlling for marital status, living conditions, working status, age at first birth and sociocultural characteristics, ethnicity, parity and level of education remained significant factors determining whether a mother gives birth at home as opposed to a clinical setting (Table 5). An interactionterm between education and ethnicity was tested in the model but appeared non-significant. The logistic regression shows that the odds for indigenous mothers to give birth at home as opposed to in a clinical setting are 10 times higher compared to the other ethnic group (ladino and 'mix' mothers). For the uptake of prenatal care, the odds for indigenous mothers were $82 \%$ lower than for the other ethnic group after controlling for parity, working status and sociocultural characteristics. However, ethnicity was only just significantly determining uptake of prenatal care (Table 6). Age at first birth, marital status, living conditions and educational level were also significantly determining uptake of prenatal care during last pregnancy.

\section{Discussion and conclusions}

Significant differences were observed in the use of pregnancy-related care between self-identified ethnic groups who have no outward markers of ethnicity (language spoken at home and dress) within Jocotán town. The results show a gradient in use of modern pregnancy- 
ARTICLE

Table 6 Odds ratios (with 95\% CIs) from a logistic regression analysis of the probability of taking up prenatal care during last pregnancy among mothers in Jocotán town, 2001

\begin{tabular}{lrll}
\hline Covariate* & \multicolumn{1}{l}{ OR } & $95 \%$ CI & $p$ \\
\hline 'Mixed' or ladino & 1.00 & & \\
Being indigenous & 0.18 & $0.03-1.12$ & $<0.06$ \\
No education & 1.75 & $0.32-9.90$ & NS \\
Primary education & 52.47 & $3.82-72.36$ & $<0.005$ \\
Secondary or higher education & 1.00 & & \\
Age at first birth & 1.01 & $1.00-1.02$ & $<0.05$ \\
Living conditions & 1.23 & $1.04-1.47$ & $<0.01$ \\
Not being married or in union & 0.17 & $0.03-0.83$ & $<0.03$ \\
Log likelihood & -49.84 & & \\
\hline
\end{tabular}

* Other controls included in the model were the woman's parity, sociocultural characteristics and working outside the house. NS, not significant; OR, odds ratio.

related care services, with ladino mothers being more likely to take up pre- and postnatal care, to deliver in a hospital and to be seen by a doctor or nurse during their pregnancy. Indigenous women are the least likely to make use of modern pregnancy-related care, and mothers of 'mixed' ethnicity demonstrate an intermediate reproductive behaviour. The results confirm previous suggestions that ethnic and educational differences are likely to persist even when barriers such as access in terms of distance to services are removed as in Jocotán town. However, (unmeasured) socioeconomic and sociocultural factors remain important in determining use of modern pregnancyrelated care. These include financial affordability of the private pregnancy-related care services and transportation facilities such as availability of a car in order to get to the hospital in Chiquimula. Other barriers such as discriminatory treatment of the staff in health facilities mainly used by ladinos, husbands' or family's objection, traditional health beliefs and fear and embarrassment about being examined by male ladino staff could explain the ethnic differences on a small scale. ${ }^{13,21-23}$ However, these explanations could not be verified by the question for reasons behind non-use of pre- and postnatal care, and more in-depth interviewing should be able to clarify this.

Overall, use of modern pregnancy-related care services was high in Jocotán. However, discussions with key informants in the study area during the many months spent in Jocotán revealed that the care at the GHC is perceived to be of low quality due to lack of staff, long waiting times, limited time for consultation and information, and the condescending attitude of some of the staff towards the patients. Despite these perceptions, the GHC remains the main modern pregnancy-related care provider for the indigenous population, representing the majority in this area. 'Mix' and ladino mothers also access the GHC but more often when a child is ill; they use the GHC as an additional service provider for pregnancy-related care. The most likely reason for these observations is that the GHC provides services free of charge, as for most indigenous people in Guatemala modern health care is considered a luxury. ${ }^{24}$ This suggests that financial constraints will limit the women, who no longer have sociocultural barriers to overcome, from accessing the services they might consider to be of better quality.

This study shows that ladino mothers are more likely to seek prenatal care compared to indigenous mothers, whereas a recent study showed that most mothers (96\%) in all ethnic groups did get some prenatal care at some stage during their pregnancy. ${ }^{7}$ All the mothers who did not take up prenatal care, except three, were indigenous. The three non-indigenous mothers had been reluctant to get prenatal care because they experienced an unwanted pregnancy. One-third of the indigenous mothers who did not use prenatal care had their last delivery in their aldea and did not report the traditional birth attendants' visits during that pregnancy. The other two-thirds of indigenous mothers who did not use prenatal care originated from an aldea and lived in the poorer districts of El Mitch or El CementerioNuevo. It was unlikely that these mothers did not see anyone during their pregnancy. From in-depth interviews with service providers in Jocotán, it appeared that women who have moved to Jocotán from the aldeas are reluctant to report their traditional practices and continued reliance on the traditional birth attendant.

Only a limited amount of information on pregnancyrelated care was collected in the two nearby aldeas. The traditional birth attendant from Pacrén, who had been enrolled on a training course for 2 years, reported having a great responsibility in her aldea and was disappointed by the lack of financial remuneration. The conditions of pregnancyrelated care in these aldeas are poor despite their close proximity to Jocotán but are probably better than in most of the aldeas, all located further from Jocotán. Even though the data for the aldeas were collected in 1994, they still reflect the reality in most remote rural areas in Guatemala 7,24 and represent the conditions of pregnancy-related care for $80 \%$ of the population in the Ch'orti area. ${ }^{19}$ The conditions of pregnancy-related care in the aldeas are worse than in the rural areas of the north-eastern region, which might suggest that the health care among the indigenous Ch'orti population is different from the rest of the region or that the Ch'orti are under-represented in the DHS sample.

The differences between Jocotán and the aldeas could well be explained by the unequal governmental provision of health and education and problems with access to services from the aldeas. ${ }^{24}$ The differences in the uptake of modern pregnancy-related care among self-identified ethnic groups in Jocotán is striking. Indigenous women are much more likely to give birth at home and, contrary to the uptake of prenatal care, socioeconomic factors do not seem to matter as much. Cultural beliefs and customs might still play an important role in the decision where to give birth. The uptake of prenatal care was mainly determined by socioeconomic indicators. Only the poorest women reported not having seen anyone during their pregnancy, whereas the majority of the indigenous mothers can only afford the low-quality health care services at the GHC.

According to the criteria used by the DHS, Jocotán would be considered entirely ladino. Previous studies have also indicated that ethnicity is not just a proxy of socioeconomic or educational class. ${ }^{25}$ Therefore, just using the DHS data would not permit detection of the ethnic gradation in use of pregnancy-related care services in Jocotán and disguises ethnic diversity in health outcomes. Failure to consider the extent of cultural diversity in Guatemala has already shown negative effects on the successful outcomes of public health policies. ${ }^{26}$

This study has the limitations that it is based on a small sample and was mainly focused on the town of Jocotán; however, this is a 'typical' town in this region. For the aldeas, the limited information collected for the 20-35year age group does not allow extrapolation for the older age groups. The collected data in the two surveys were based on the last birth, independently from when it occurred, which might have introduced recall errors. However, this would have equally affected all ethnic groups and does not change the main study conclusions.

Training, recognising and remunerating the traditional birth attendants whilst extending coverage of modern pregnancy care in the aldeas, improving quality of care at the GHC in Jocotán, and providing easy access to a maternity ward remain priorities in the Ch'orti area. 
Acknowledgements

The author wants to thank her supervisors Andrew Hinde and Monique Hennink and colleague Sabu Padmadas for their useful comments. She also wants to thank Mario Anzueto from the Guatemalan Office for National Statistics (INE) for providing background information and Brent Metz and Laura Kriegstrom for allowing the use of the geographical map of the Ch'orti area

Statements on funding and competing interest

Funding. This research was funded by the UK Economic and Socia Research Council (Award No. PTA 030-2002-00526) and the Programme of Opportunities and Choices at the University of Southampton, Southampton, UK

Competing interests. None identified.

References

1 Schieber B, Stanton C. Estimates of maternal mortality in Guatemala 1996-1998. SR-00-01. Measure Evaluation Project, Guatemala, March 2000

2 Kestler E, Ramirez L. Pregnancy-related mortality in Guatemala, 1993-1996. Rev Panam Salud Publica 2000; 7: 41-46.

3 Acosta AA, Cabezas E, Chaparro JC. Present and future of maternal

4 Pan American Health Organization Country Health Profile 2001: Guatemala. 2001. http://www.paho.org [Accessed 20 October 2002]

Schieber B, Delgado H. An Intervention to Reduce Maternal and Neonatal Mortality. M1-003. Guatemala City, Guatemala: INCAP/PAHO, 1993

6 Glei DA, Goldman N. Understanding ethnic variation in pregnancyrelated care in rural Guatemala. Ethn Health 2000; 5: 5-22.

Goldman N, Glei DA. Evaluation of midwifery care: results from a survey in rural Guatemala. Soc Sci Med 2003; 56: 685-700.

8 Pebley AR, Goldman N, Rodriguez G. Prenatal and delivery care in childhood immunization in Guatemala: do family and community matter? Demography 1996; 32: 231-247.

9 Lang JB, Elkin ED. A study of the belief and birthing practices of traditional midwives in rural Guatemala. J Nurse Midwifery 1997; 42 25-31.

10 Steele D. Guatemala. In: Psacharopoulos G, Patrinos HA (eds) Indigenous People and Poverty in Latin America: An Empirical Analysis. Washington, DC: World Bank, 1994; 105-140.

11 Celik Y, Hotchkin DR. The socio-economic determinants of maternal health care utilization in Turkey. Soc Sci Med 2000: 50: 1797-1806.

2 Cleland J, van Ginneken JK. Maternal education and child survival in developing countries. The search for pathways of influence. Soc Sci Med 1988; 27: 1357-1368.

13 Cosminsky S. Women and health care on a Guatemalan plantation. Soc Sci Med 1987; 25: 1163-1173.

14 Barry T. Inside Guatemala. Albuquerque, NM: The InterHemispheric Education Resource Centre, 1992.

15 Warren KB. The Symbolism of Subordination: Indian Identity in a Guatemalan Town. Austin, TX: University of Texas Press, 1978

16 Wearne P. The Maya of Guatemala. London, UK: Minority Rights Group International, 1994.

17 Early JD. Revision of Ladino and Maya Census Populations of Guatemala, 1950 and 1964. Demography 1974; 11: 105-117.

18 Lovell GW, Lutz CH. The Maya Population of Guatemala. In: Pebley AR, Rosero-Bixby L (eds), Demographic Diversity and Change in the Central American Isthmus. Santa Monica, CA: Rand, 1997; 117-132.

19 Instituto Nacional de Estadística (INE). Censos Nacionales XI de Población y VI de Habitación 2002. Características de la Población de los Locales de Habitación Censados. Guatemala City, Guatemala: INE 2003 .

20 Cosminsky S. Maya midwives of Southern Mexico and Guatemala. In: Huber BR, Sandstrom AR (eds), Mesoamerican Healers. Austin, TX: University of Texas Press, 2001

21 Hurtado E, Sáenz de Tejada ES. Relations between government health workers and traditional midwives in Guatemala. In: Huber BR Sandstrom AR (eds), Mesoamerican Healers. Austin, TX: University of Texas Press, 2001

22 Instituto de Nutrición de Centro América y Panamá (INCAP), Ministerio de Salud Pública y Asistencia Social (MSPAS), USAID, DHS/Macro International. Salud Materno Infantil en Cuatro Proveedores de Salud. Guatemala City, Gudos dela INCAP, 1997. Proveedores de Salud. Guatemala City, Guatemala: INCAP, 1997.

23 Gragnolati M, Marini A. Health and Poverty in Guatemala. World Bank Policy Research Working Paper 2966. http://econ.worldbank. org [Accessed 14 April 2003].

24 Metz B. Politics, population and family planning in Guatemala: Ch'orti Maya experiences. Hum Organ 2001; 60: 259-271.

25 Beckett M, Pebley AR. Ethnicity, language, and economic well-being in rural Guatemala. Rural Sociol 2003; 68: 434-458.

26 Justice J. Policies, Plans, and People: Foreign Aid and Health Development. Berkeley, CA: University of California Press, 1986.

\section{But is she positive?}

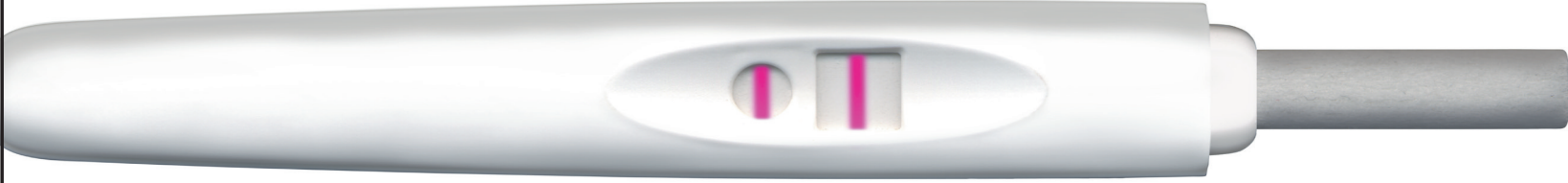

Your next patient is pregnant but doesn't want to be.

Where next? As a registered charity since 1968, bpas has offered affordable abortion care for women. We provide almost 50,000 abortions a year (including service agreements) and can offer all the professional help your patient needs.

bpas has a nationwide network of clinics and consultation centres. There are no long waits for appointments. We can offer a choice of times, clinics and procedures. All it takes to arrange an appointment is one call to the bpas Actionline on 08457304030.

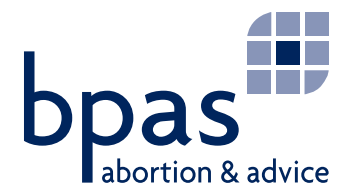

ACTIONLINE 08457304030

bpas positively the best service 